\title{
Effectiveness of intervention for low back pain in female caregivers in nursing homes: a pilot trial based on multicenter randomization
}

\author{
Hiroharu Kamioka • Hiroyasu Okuizumi • \\ Shinpei Okada $\cdot$ Ryosuke Takahashi $\cdot$ \\ Shuichi Handa $\cdot$ Jun Kitayuguchi $\cdot$ Yoshiteru Mutoh
}

Received: 8 June 2010/Accepted: 16 July 2010/Published online: 13 August 2010

(C) The Japanese Society for Hygiene 2010

\begin{abstract}
Objectives Although the importance of stretching exercise for pain-relieving and patient education is well documented for chronic lumbago patients, it is uncertain how effective on-the-job training (OJT) is for female caregivers in nursing homes. In the present pilot trial based on multicenter randomization, we evaluated the intervention effect of a lecture and stretching exercise on caregivers in nursing homes.

Methods Eighty-eight female caregivers (four nursing homes) volunteered to participate in this study, and they
\end{abstract}

\footnotetext{
H. Kamioka $(\bowtie)$

Faculty of Regional Environment Science,

Tokyo University of Agriculture, 1-1-1 Sakuragaoka,

Setagaya-ku, Tokyo 156-8502, Japan

e-mail: h1kamiok@nodai.ac.jp

H. Okuizumi $\cdot$ S. Handa

Mimaki Onsen (Spa) Clinic, Tomi, Nagano, Japan

S. Okada

Physical Education and Medicine Research Foundation,

Nagano, Japan

R. Takahashi

College of Science and Technology,

Nihon University, Chiba, Japan

J. Kitayuguchi

Physical Education and Medicine Research Center Unnan,

Unnan, Shimane, Japan

Y. Mutoh

Department of Physical and Health Education,

Graduate School of Education, The University of Tokyo,

Tokyo, Japan
}

were separated into two groups randomly. For the intervention group, guidance by an orthopedist and an exercise instructor were provided as one OJT, and stretching exercises for only 6 min every day were recommended for low back pain prevention to the caregivers. Low back pain visual analogue scale (VAS), physical fitness, and mental and physical health were compared at baseline and immediately after the intervention.

Results A total of 29 (33\%) participants withdrew by 12 weeks. Regarding the reasons for withdrawal, 28 participants resigned, and one took a leave of absence due to exacerbation of lumbago. Adherence to the stretching exercises was $2.3 \pm 1.3$ (mean $\pm \mathrm{SD}$ ) times per week. No significant differences were seen for any outcome measurements. The high adherence group ( $\geqq 3$ times per week) did not show a change in the VAS, but the low adherence group $(<3$ times per week) and control group showed a tendency towards an increased score $(p=0.068)$.

Conclusions Even with the conduct of one OJT, and exercises of only 6 min every day, the adherence of caregivers was low, and there appeared to be few effects of the OJT.

Keywords Feasibility - On-the-job training $\cdot$ Female caregiver $\cdot$ Low back pain

\section{Introduction}

In recent years, Japan has had a fast-aging population with the greatest longevity in the world. According to the statistics of the Japanese Health, Labor, and Welfare Ministry, the proportion of the elderly aged 65 years or older reached $20.8 \%$ in fiscal 2006 , and is estimated to reach $39.6 \%$ in fiscal 2050 [1]. 
In such an aged society, various health issues occur in caregivers in nursing homes. In particular, female caregivers have been reported to be at high risk of having high blood pressure [2] and coronary heart disease [3]. Additionally, caregivers have high prevalence rates of low back pain and a high incidence of worker's compensation claims for back injuries [4-6]. Low back pain is frequent in various occupations, its presence being related to activities requiring repetitive lifting and repeated activities for which anomalous postures tend to be adopted [7]. Such characteristics of work are common among nursing caregivers [8]. The prevalence of this condition in nursing is high in comparison with that in other occupations and in relation to other types of work [9]. Risk factors include physical workload such as the manual lifting and transferring of patients, working conditions such as working time and rest during the night shift, and the working environment [4]. Among these factors, frequent exposure to the manual lifting and transferring of patients is a widely recognized risk factor.

Of note, for female caregivers, it was reported that dissatisfaction with working conditions and the workplace environment was high [4], mental stress from work and human relations tended to be high [8, 9], and physical fitness elements such as flexibility and muscular strength were low [10]. Caregivers in nursing homes perform shift work, including night work. In shift workers, a high risk of sleep interruption was reported [11]. A study reported that caregivers who provided care at night suffered from a general sense of fatigue, physical disorders, and reduced mental energy compared with women employed in other areas [12]. A systematic review indicated that female caregivers had high levels of burden and depression, and low levels of subjective well-being and physical health [13]. Therefore, it is necessary that the issue of health in caregivers in nursing homes should include not only low back pain, but also mental and physical health status, and ways of interpreting these factors.

There are some exercise interventions for the lumbago patient [14-16], but so far there are few randomized controlled trials of exercise interventions for caregivers in nursing homes. Furthermore, there is no study that has assumed mental and physical health status as secondary outcome measurements. In a recent study [17], there was an effort to attach great importance to the feasibility. Because the possibility of generalization is a serious matter, we considered that we needed to examine an intervention program that entailed few burdens to caregivers in a realistic care scenario.

In the present pilot trial, based on multicenter randomization, we evaluated the intervention effect of a lecture and stretching exercise on caregivers in nursing homes.

\section{Methods}

Participants and randomization

Figure 1 shows participant recruitment and the research process. This study was announced by the sales staff of Hakujuji Corporation for 17 special elderly nursing homes around the Tokyo metropolitan area between May and August 2009. Of the 17 nursing homes, four volunteered to participate in this study. Each chief director approved the participation of the nursing home. The eligibility criteria included female caregivers who performed night work, and had no contraindication for exercise. Years of experience and the working conditions regarding official or unofficial employment were not classified in the exclusion criteria. Of the 88 female caregivers in the target population, all $(100 \%)$ consented to participate when provided with enough explanation.

The nursing homes were assigned to a control group or an intervention group (complete blinding for all participants). Of the 88 volunteers, 44 were randomly assigned by lottery to the intervention group and 44 to the control group. Two "signed (intervention group)" and two "unsigned (control group)" sticks, which were drawn from sealed boxes, were assigned to the numbers for the nursing homes. The lottery operation was performed by a third person; namely, a person other than the investigators or the person in charge of intervention or evaluation. The concealment was confirmed by the reports delivered after all the assignments were finished.

\section{Research design}

This was a multicenter, randomized pilot trial comparing comprehensive intervention, based on a lecture and stretching exercise, to non-education for the participants (facilities). The intervention group was divided into high ( $n=23)$ and low $(n=15)$ adherence groups, and subgroup

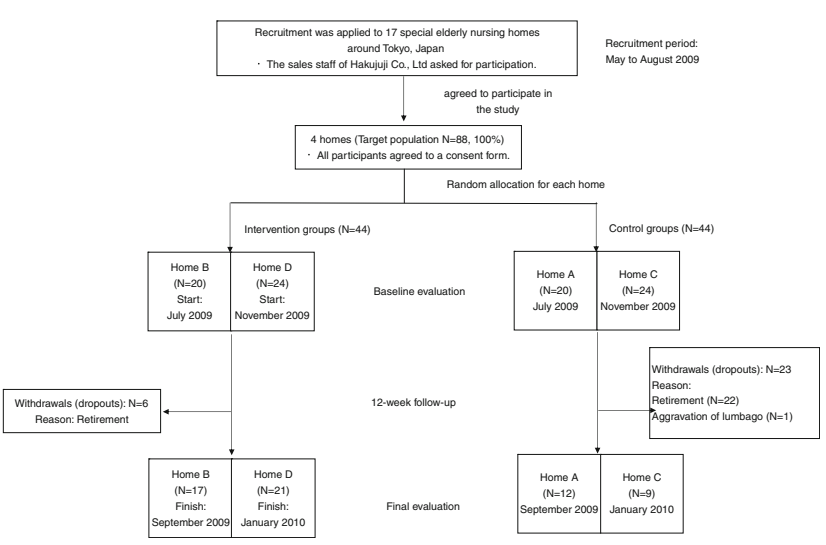

Fig. 1 Study flow diagram 
analysis was performed to detect differences between the high and low groups and the control group. The trial procedure, analysis, and description were reported according to the CONSORT statement (extension to cluster randomized trials) [18] and the CLEAR NPT checklist (a checklist to evaluate a report of a nonpharmacological trial) [19].

\section{Setting and intervention}

The intervention program and the evaluation were carried out in each nursing home, the locations of which were as follows: nursing home A (Setagaya-ku, Tokyo), nursing home B (Koshigaya City, Saitama Prefecture), nursing home C (Konosu City, Saitama Prefecture), and nursing home D (Tomi City, Nagano Prefecture). All were special elderly nursing homes that were run by a social welfare corporation.

The intervention program consisted of a lecture and stretching exercise (Table 1). Because the participants performed shift work, the same intervention program was conducted a total of three times.

The lecture, which lasted for $30 \mathrm{~min}$, was given by an orthopedist with extensive clinical experience (20 years). The lecture contained information on risk factors, biomechanics of care-movement, treatment, and recommended exercise, and the lecturer presented the information with original, legible learning material, and adequately answered the questions of the participants.
The stretching exercise program consisted of classical exercises aimed at the reduction and prevention of lumbago. The program contained the original eight elements of stretching based on the William and Mackenzie exercises utilized widely in the kinesitherapy of rehabilitation (Table 1). An original color leaflet was distributed to all the participants so that they did not forget the exercises. In addition, an original DVD of the series of exercises that would be performed was distributed to each nursing home for the participants to watch. Participants could perform the exercises alone for around $6 \mathrm{~min}$ (about $30 \mathrm{~s}$ per one element). The reason why strength training was not imposed on a participant was to reduce the feeling of burden as much as possible from the viewpoint of generalization and feasibility in nursing homes in Japan. The exercise instructions were given by two expert trainers (over 7 years of instruction experience). The intervention was included in on-the-job training (OJT) for the entire staff in each nursing home, and the male caregivers, office workers, and cleaning staff also participated.

Instructions on daily life

Participants were asked, in a relatively nonforceful and nonsupervisory manner,, to perform the stretching exercise every day, giving the first priority to the participant's own personal free will. Participants in the control groups were

Table 1 Intervention program

\begin{tabular}{ll}
\hline Contents & \\
\hline Lecture $^{\mathrm{a}}$ (30 min) & \\
Statistical data about low back pain & \\
Risk factors for low back pain in caregivers' daily actions & \\
Biomechanical explanation of spinal structure & \\
Low back pain and medical treatment & \\
Recommendations for how to move in caregiving & Main parts \\
Recommended exercise & \\
\hline Actions & The lower back \\
\hline Stretching exercise ${ }^{\mathrm{b}}$ (60 min) & Gluteus maximus \\
1. Leaning forward & Lateral muscles of the hip \\
2. Holding a knee in the arms & Back thigh and hamstring \\
3. Holding knee with trunk-twist & The Achilles' tendon \\
4. Leaning forward with a single leg put forward & The upper back (especially around shoulder blade) \\
5. Ankle stretching & Muscles around neck \\
6. Jutting arms forward while crossing both hands & Relaxing the muscles around the waist \\
7. Turning one's face & \\
8. Leaning back slightly &
\end{tabular}

${ }^{a}$ The lecturer was an orthopedist (clinical experience 20 years)

b Stretching instructions were given by two expert trainers (instructor experience over 7 years) based on the William and Mackenzie exercise system 
also encouraged to keep to their same previous daily activities for 12 weeks.

\section{Definition of low back pain}

It was decided to use chronic pain as the definition of low back pain in this study. Medical examinations such as $\mathrm{X}$-ray diagnosis and/or treatments were not performed, and the causal disease of the pain was not specified.

\section{Outcome measurements}

The baseline assessment was performed in July and November of 2009, and the final assessment was performed after a 12-week follow-up in September 2009 and January 2010. A $10-\mathrm{cm}$ visual analogue scale (VAS) for low back pain was the main outcome measurement. The score evaluation ranged from 0 (not at all painful) to 10 (greatest pain). Anteflexion was the secondary outcome. Other outcome measurements included physical indices, physical strength, and physical and psychological fitness. The physical indices were height, weight, and body mass index (BMI).

Measures of strength were grip strength (Sensor EG230; Sakai, Tokyo, Japan) and anteflexion. The grip force $(\mathrm{kg})$ was measured twice on the right and left sides, and the mean of each maximum was adopted. At first, participants pressed their buttocks and back against a wall and, for the measurement of anteflexion (T-2069; Toei Light, Tokyo, Japan), took long sitting position. They put both hands on the instrument and pushed to initiate anteflexion. The distance that changed in response to this movement was measured. Participants took adequate breaks, and the procedure was carried out twice, after which the maximum measurement $(\mathrm{cm})$ was adopted. Furthermore, it was evaluated whether the fingers of both hands could reach the floor (finger-floor distance: FFD) from a standing position during anteflexion. If participants were wearing hips reinforcement belt, they took it off before FFD was measured.

The Center for Epidemiologic Studies Depression Scale (CES-D) [20] was used to assess depressive symptoms. Participants were asked, while in a quiet and private room, to answer frankly questions about their mood states during the past week. This questionnaire consisted of 20 questions answered on a 0 - to 3-points Likert scale, such that the lowest total score for depressive symptoms would be 0 points, and the maximum total score would be 60 points.

For health-related quality of life (QOL), the SF-8 (MOS Short-Form 8-Item Health Survey) [21] was used. This questionnaire is comprised of eight questions (answered on a 6- or 5-point Likert scale), for which the reliability and validity have been reported. It had two summary scores: the physical health score (PHS), and the mental health score (MHS). The score algorithm (weighting differed by questions and items) for each question used a scoring method defined in the test guidelines. Higher PHS and MHS scores indicated a better state of health.

All the measurements of physical strength and physical indices were performed by skilled evaluators with more than 3 years of experience. All measurements were carried out by a single evaluator after sufficient preliminary training, because it was possible that the evaluator's skill could influence the evaluation. The evaluator was a different person than the interventionist, and blinding was applied to the evaluator, but not to the interventionist.

At the last evaluation, the participants were interviewed about their adherence (percent compliance during the study period) with the stretching exercise . Rates of adherence showed the percent compliance with the exercise for the intervention period.

Regarding ethical considerations, the participants were sufficiently informed of the study plan by written and verbal means before their written consents were obtained. The information included the fact that they were allowed to quit the study at any time, and an explanation of all the possible disadvantages of entering the study. To avoid giving an unfair impression to the participants, those in the control groups received the same educational program as the intervention groups after the final evaluation.

The methodology of this study was approved by the Ethics Board of Tokyo University of Agriculture. The present study was registered as ID 000001836 by the University Hospital Medical Information Network Clinical Trials Registry (UMIN-CTR) in Japan.

\section{Statistical analysis}

Because the VAS of low back pain was the primary outcome measurement, power calculations were conducted for the primary outcome. The standard deviation of the mean was approximately $2.0 \mathrm{~cm}$, and the significant difference level between groups in the present study was $2.0 \mathrm{~cm}$. Statistical power was set such that the probability of a type 1 error $(\alpha)$ was $5 \%$ and that of a type 2 error $(\beta)$ was $20 \%$. The required sample size was calculated to be 16 or more participants in each arm.

Furthermore, in a subgroup analysis, the intervention group was divided into two groups based on adherence to the stretching exercises. The cutoff point was set as three times per week to be similar to the median.

A two-sample $t$ test (Welch test) was employed for comparisons between groups with continuous variables in the analysis. Fisher's exact probability test, the MannWhitney test, and the Kruskal-Wallis test were performed with discrete variables. A repeated-measures analysis of variance (ANOVA) was used to investigate the differences in changes ( 2 groups $\times 2$ times for the per-protocol 
analysis, and 3 groups $\times 2$ times for subgroup analysis) between groups. Differences within and among groups were judged significant when the significance levels were $5 \%$ or less. SPSS $15.0 \mathrm{~J}$ for Windows (SPSS, Chicago, IL, USA) was used for the statistical analysis.

\section{Results}

Table 2 shows a comparison of the baseline characteristics of each nursing home. Only the years of experience of caregivers were significantly different $(p<0.05)$, and the number was greater for nursing home $\mathrm{D}(8.2 \pm 5.0$ years $)$ than for nursing home A $(4.3 \pm 2.9$ years $)$ and nursing home $\mathrm{C}(4.4 \pm 3.4$ years $)$. For the other variables, there were no significant differences between the nursing homes. For the VAS at baseline, there were only two (2.3\%) caregivers without low back pain.

Table 3 shows the comparison of baseline characteristics between follow-up accomplishment and withdrawal in each group. A total of six (14\%) participants withdrew in the intervention group, and there was no significant difference between the follow-up accomplishment and withdrawal groups. All 6 withdrawals were due to resignations from their jobs. A total of 23 (52\%) participants withdrew in the control group, and BMI and grip force were significantly higher $(p<0.05)$ in the withdrawal group than in the followup accomplishment group. In addition, the VAS of low back pain tended to be higher $(p=0.085)$ in the withdrawal group. Regarding reasons for withdrawal, 22 participants resigned, and one had a leave of absence due to exacerbation of lumbago. We were not able to specify the reasons for resignation in caregivers in the intervention group and the control group because it was personal information.

Table 4 shows the results of the per-protocol analysis of differences between the intervention group and the control group. No significant difference between the groups was seen for any outcome measurements. The VAS, as the main outcome measurement, tended to be high in both groups. The rate of adherence to the stretching exercise was $2.7 \pm 1.3$ times per week (mean $\pm \mathrm{SD}$ ).

Table 5 shows the results of the subgroup analysis. The high adherence group did not have a change in the VAS, but the low adherence group and control group had a tendency towards an increased score $(p=0.068)$. The high adherence group had a tendency towards improvement in grip force, but the low adherence group and control group had a tendency towards reduced grip force $(p=0.054)$.

There were no adverse events during the entire study period. No data were missing and there were no examples of nonvalid data in any of the outcome measurements. The intervention expense in this study was estimated to be approximately 1,000 US dollars (500 dollars $\times 2$ times) per each nursing home, if it was a Japanese common-sense reward. The breakdown in expenses was for the lecture charges of the doctor, the exercise guidance charges of the trainer, and the materials and transportation expenses. In reality, the compensation was not paid because it was the co-authors who intervened.

Table 2 Baseline characteristics of participants

\begin{tabular}{llllll}
\hline & Nursing home A & Nursing home B & Nursing home C & Nursing home D & Total \\
\hline$N$ & 20 & 20 & 24 & 24 & 88 \\
Age (years) & $37.8 \pm 16.2$ & $33.9 \pm 15.3$ & $33.2 \pm 10.1$ & $39.9 \pm 10.0$ & $36.2 \pm 13.0$ \\
Years of experience (years) & $4.3 \pm 2.9 \mathrm{a}$ & $5.7 \pm 5.3$ & $4.4 \pm 3.4 \mathrm{~b}$ & $8.2 \pm 5.0 * \mathrm{c}$ & $5.7 \pm 4.5$ \\
VAS of low back pain (10-cm) & $3.8 \pm 2.6$ & $4.5 \pm 2.2$ & $4.2 \pm 2.0$ & $4.7 \pm 1.5$ & $4.3 \pm 2.1$ \\
Height (cm) & $157.2 \pm 6.0$ & $156.8 \pm 6.9$ & $158.5 \pm 5.7$ & $159.6 \pm 5.1$ & $158.1 \pm 5.9$ \\
Weight (kg) & $54.2 \pm 10.2$ & $52.4 \pm 7.8$ & $61.8 \pm 17.9$ & $62.1 \pm 13.7$ & $58.0 \pm 13.8$ \\
BMI & $21.9 \pm 3.5$ & $21.3 \pm 2.8$ & $24.4 \pm 5.8$ & $24.4 \pm 5.1$ & $23.1 \pm 4.7$ \\
Grip force (kg) & $27.2 \pm 4.6$ & $27.6 \pm 4.6$ & $26.4 \pm 5.4$ & $28.5 \pm 4.6$ & $36.8 \pm 7.6$ \\
Sitting trunk flexion test (cm) & $31.4 \pm 10.9$ & $36.4 \pm 10.1$ & $37.4 \pm 8.9$ & $35.4 \pm 4.8$ \\
FFD (touch the floor with fingers) & $13(65.0 \%)$ & $15(75.0 \%)$ & $16(66.7 \%)$ & $21(87.5 \%)$ & $65(73.9 \%)$ \\
Self-assessment of depression (scores) & $14.8 \pm 6.4$ & $17.1 \pm 7.7$ & $17.3 \pm 9.5$ & $16.6 \pm 5.0$ \\
Scores based on SF-8 & & & & $4.5 \pm 7.3$ \\
Physical fitness score (scores) & $47.4 \pm 6.3$ & $45.2 \pm 4.7$ & $46.4 \pm 8.9$ & $47.0 \pm 5.6$ & $46.8 \pm 5.4$ \\
Psychological fitness score (scores) & $48.3 \pm 4.6$ & $47.6 \pm 8.1$ & $45.3 \pm 8.7$ & $46.9 \pm 6.9$ \\
\hline
\end{tabular}

Continuous variables are shown as means \pm standard deviation. Categorical variables are shown as frequency (percentage)

Multiple comparison of the mean was assessed by the Tukey test and differences in proportions were assessed by the Kruskal-Wallis test $V A S$ visual analog scale, $B M I$ body mass index, $F F D$ finger-floor distance

* $p<0.05 ; \mathrm{c}>\mathrm{a}, \mathrm{b}$ 
Table 3 Baseline characteristics of participants in each group

\begin{tabular}{|c|c|c|c|c|c|c|}
\hline & \multicolumn{3}{|l|}{ Intervention group } & \multicolumn{3}{|l|}{ Control group } \\
\hline & $\begin{array}{l}\text { Follow-up } \\
\text { accomplishment }\end{array}$ & Withdrawal & $p$ value & $\begin{array}{l}\text { Follow-up } \\
\text { accomplishment }\end{array}$ & Withdrawal & $p$ value \\
\hline$N(\%)$ & $38(86 \%)$ & $6(14 \%)$ & - & $21(48 \%)$ & $23(52 \%)$ & - \\
\hline Age (years) & $38.1 \pm 13.5$ & $30.8 \pm 5.4$ & 0.200 & $38.2 \pm 14.0$ & $32.6 \pm 12.3$ & 0.163 \\
\hline Years of experience (years) & $7.3 \pm 5.3$ & $5.6 \pm 5.0$ & 0.475 & $4.5 \pm 3.3$ & $4.3 \pm 3.0$ & 0.826 \\
\hline VAS of low back pain $(10-\mathrm{cm})$ & $45.3 \pm 19.8$ & $51.7 \pm 9.8$ & 0.444 & $33.8 \pm 24.5$ & $45.7 \pm 19.8$ & 0.085 \\
\hline Height $(\mathrm{cm})$ & $158.6 \pm 5.9$ & $156.3 \pm 7.4$ & 0.390 & $156.3 \pm 6.5$ & $159.4 \pm 4.8$ & 0.087 \\
\hline Weight $(\mathrm{kg})$ & $57.8 \pm 12.7$ & $57.0 \pm 10.3$ & 889 & $52.9 \pm 9.9$ & $63.2 \pm 17.7$ & 0.023 \\
\hline BMI & $22.9 \pm 4.5$ & $23.3 \pm 4.0$ & 0.834 & $21.6 \pm 3.6$ & $24.7 \pm 5.8$ & 0.041 \\
\hline Grip force $(\mathrm{kg})$ & $28.4 \pm 4.6$ & $26.1 \pm 3.6$ & 0.256 & $25.2 \pm 4.4$ & $28.2 \pm 5.2$ & 0.047 \\
\hline Sitting trunk flexion test $(\mathrm{cm})$ & $36.1 \pm 8.8$ & $40.2 \pm 7.7$ & 0.292 & $33.8 \pm 8.2$ & $35.5 \pm 11.9$ & 0.584 \\
\hline FFD (touch the floor with fingers) & $31(81.6 \%)$ & $5(83.3 \%)$ & 0.700 & $16(76.2 \%)$ & $13(56.5 \%)$ & 0.145 \\
\hline Self-assessment of depression (scores) & $17.1 \pm 6.1$ & $15.3 \pm 7.8$ & 0.539 & $16.4 \pm 7.8$ & $16.2 \pm 8.9$ & 0.949 \\
\hline \multicolumn{7}{|l|}{ Scores based on SF-8 } \\
\hline Physical fitness score (scores) & $46.3 \pm 5.3$ & $45.2 \pm 5.0$ & 0.635 & $47.8 \pm 7.3$ & $46.0 \pm 8.3$ & 0.444 \\
\hline Psychological fitness score (scores) & $46.7 \pm 6.5$ & $50.2 \pm 7.7$ & 0.232 & $45.8 \pm 6.9$ & $47.4 \pm 7.5$ & 0.465 \\
\hline
\end{tabular}

Continuous variables are shown as means \pm standard deviation. Categorical variables are shown as frequency (percentage)

The comparison of FFD data was assessed by the $\chi^{2}$ test

The mean comparisons of other variables were assessed by $t$ test

Table 4 Effect of intervention compared with control group

\begin{tabular}{|c|c|c|c|c|c|}
\hline & \multicolumn{2}{|c|}{ Intervention group $(N=38)$} & \multicolumn{2}{|c|}{ Control group $(N=21)$} & \multirow[t]{2}{*}{$p$ value } \\
\hline & Baseline & After 12 weeks & Baseline & After 12 weeks & \\
\hline Age (years) & $38.1 \pm 13.5$ & - & $38.2 \pm 14.0$ & - & - \\
\hline Years of experience (years) & $7.3 \pm 5.3$ & - & $4.5 \pm 3.3$ & - & - \\
\hline VAS of low back pain $(10-\mathrm{cm})$ & $4.5 \pm 2.0$ & $5.0 \pm 1.9$ & $3.4 \pm 2.5$ & $4.1 \pm 2.5$ & 0.653 \\
\hline Weight (kg) & $57.8 \pm 12.7$ & $57.2 \pm 12.0$ & $52.9 \pm 9.9$ & $53.2 \pm 9.8$ & 0.069 \\
\hline BMI & $22.9 \pm 4.5$ & $22.7 \pm 4.3$ & $21.6 \pm 3.6$ & $21.7 \pm 3.6$ & 0.070 \\
\hline Grip force $(\mathrm{kg})$ & $28.4 \pm 4.6$ & $27.6 \pm 4.5$ & $25.2 \pm 4.4$ & $24.9 \pm 4.8$ & 0.569 \\
\hline Sitting trunk flexion test $(\mathrm{cm})$ & $36.1 \pm 8.8$ & $38.1 \pm 9.2$ & $33.8 \pm 8.2$ & $34.6 \pm 10.0$ & 0.507 \\
\hline FFD (touch the floor with fingers) & $31(81.6 \%)$ & $30(78.9 \%)$ & $16(76.2 \%)$ & $18(85.7 \%)$ & 0.199 \\
\hline Self-assessment of depression (scores) & $17.1 \pm 6.1$ & $14.7 \pm 6.6$ & $16.4 \pm 7.8$ & $15.8 \pm 11.1$ & 0.406 \\
\hline \multicolumn{6}{|l|}{ Scores based on SF-8 } \\
\hline Physical fitness score (scores) & $46.3 \pm 5.3$ & $32.5 \pm 11.7$ & $47.8 \pm 7.3$ & $32.3 \pm 9.8$ & 0.831 \\
\hline Psychological fitness score (scores) & $46.7 \pm 6.5$ & $37.9 \pm 8.6$ & $45.8 \pm 6.9$ & $41.1 \pm 9.0$ & 0.424 \\
\hline
\end{tabular}

Continuous variables are shown as means \pm standard deviation. Categorical variables are shown as frequency $(\%)$

The Mann-Whitney test was conducted for FFD data to test the difference in 3-month change between the groups

Differences in 3-month change between the groups for the other variables were tested by repeated two-way analysis of variance (ANOVA)

\section{Discussion}

There has been an RCT about depression in persons undertaking family care [22]; however, a pilot study like the present RCT to examine lumbago in female caregivers in nursing homes has not been performed. Worldwide, the aging population is rapidly increasing, and, for the Japanese, a large percentage of people are in nursing home care. It is therefore thought that knowledge from this study will be useful in the future for developed nations, where extension of life is observed.

In the present study, resignations by caregivers, which totaled $32 \%(22 / 88)$ participants in 12 weeks, suggested that the occupation of Japanese caregivers incurred serious problems . Because the reason for resignation was personal information in this study, it could not be checked, but it 
Table 5 Subgroup analysis according to adherence

\begin{tabular}{|c|c|c|c|c|c|c|c|}
\hline & \multirow{2}{*}{\multicolumn{2}{|c|}{$\begin{array}{l}\text { High adherence } \\
\text { group }(N=23) \\
\geqq 3 \text { times/week }\end{array}$}} & \multirow{2}{*}{\multicolumn{2}{|c|}{$\begin{array}{l}\text { Low adherence } \\
\text { group }(N=15) \\
<3 \text { times/week }\end{array}$}} & \multirow{2}{*}{\multicolumn{2}{|c|}{ Control group $(N=21)$}} & \multirow[t]{3}{*}{$p$ value } \\
\hline & & & & & & & \\
\hline & Baseline & After 12 weeks & Baseline & After 12 weeks & Baseline & After 12 weeks & \\
\hline Age (years) & $40.8 \pm 12.1$ & - & $34.1 \pm 14.9$ & - & $38.2 \pm 14.0$ & - & - \\
\hline Years of experience (years) & $7.5 \pm 4.9$ & - & $7.0 \pm 6.1$ & - & $4.5 \pm 3.3$ & - & - \\
\hline VAS of low back pain $(10-\mathrm{cm})$ & $5.0 \pm 1.7$ & $4.9 \pm 2.0$ & $3.8 \pm 2.3$ & $5.1 \pm 1.8$ & $3.4 \pm 2.5$ & $4.1 \pm 2.5$ & 0.068 \\
\hline Weight (kg) & $58.5 \pm 13.0$ & $58.1 \pm 12.0$ & $56.6 \pm 12.6$ & $55.8 \pm 12.3$ & $52.9 \pm 9.9$ & $53.2 \pm 9.8$ & 0.146 \\
\hline BMI & $23.0 \pm 4.3$ & $22.9 \pm 3.9$ & $22.7 \pm 5.0$ & $22.4 \pm 5.0$ & $21.6 \pm 3.6$ & $21.7 \pm 3.6$ & 0.156 \\
\hline Grip force $(\mathrm{kg})$ & $27.9 \pm 4.6$ & $28.2 \pm 4.4$ & $29.2 \pm 4.7$ & $26.8 \pm 4.7$ & $25.2 \pm 4.4$ & $24.9 \pm 4.8$ & 0.054 \\
\hline Sitting trunk flexion test $(\mathrm{cm})$ & $36.0 \pm 9.5$ & $38.8 \pm 8.8$ & $36.3 \pm 8.1$ & $36.9 \pm 10.0$ & $33.8 \pm 8.2$ & $34.6 \pm 10.0$ & 0.464 \\
\hline FFD (touch the floor with fingers) & $20(87.0 \%)$ & $18(78.3 \%)$ & $11(73.3 \%)$ & $12(80.0 \%)$ & $16(76.2 \%)$ & $18(85.7 \%)$ & 0.183 \\
\hline Self-assessment of depression (scores) & $16.5 \pm 5.4$ & $14.1 \pm 5.2$ & $17.9 \pm 7.1$ & $15.5 \pm 8.4$ & $16.4 \pm 7.8$ & $15.8 \pm 11.1$ & 0.710 \\
\hline \multicolumn{8}{|l|}{ Scores based on SF-8 } \\
\hline Physical fitness score (scores) & $46.3 \pm 5.7$ & $32.3 \pm 12.6$ & $46.4 \pm 4.8$ & $32.8 \pm 10.5$ & $47.8 \pm 7.3$ & $32.3 \pm 9.8$ & 0.912 \\
\hline Psychological fitness score (scores) & $47.5 \pm 6.0$ & $38.7 \pm 7.5$ & $45.4 \pm 7.2$ & $36.6 \pm 10.3$ & $45.8 \pm 6.9$ & $41.1 \pm 9.0$ & 0.503 \\
\hline
\end{tabular}

Continuous variables are shown as means \pm standard deviation. Categorical variables are shown as frequency $(\%)$

The Kruskal-Wallis test was adapted for FFD data to test the difference in 3-month change between the groups

Differences in 3-month change between the groups for the other variables were tested by repeated two-way ANOVA

was thought that restrictions on salary and/or health problems due to the burden of labor, including shift work with night-work, were the main reasons. A strategy to reduce the number of resignations is very important, but studying this issue is another big problem.

Because there was a high withdrawal rate in the present study, an intention-to-treat (ITT) analysis was not performed. Because there were no extreme differences among baseline characteristics in the intervention and control groups between the follow-up accomplishment and withdrawal groups (Table 3), the intervention effect was examined by a per-protocol analysis and a subgroup analysis.

The intervention was based on the working conditions of caregivers in nursing homes, and it was also designed to be feasible for caregivers and nursing homes. To be concrete, each nursing home implemented this intervention as an OJT and, furthermore, shift work personnel were considered such that an equivalent program was performed twice. When this method was considered based on the expense of the OJT and the influence on care itself, the possibility of generalization to all nursing homes in Japan was high. Furthermore, so as to present a reduced burden to busy caregivers, with the demand for stretching exercises of only six minutes once a day for the intervention groups, strength training was not included and was assumed to have not taken place, but the adherence with the exercises was still an average of 2.3 times per week. Thus, no reduction effect for low back pain was observed and no other effects were observed because of poor adherence. In the subgroup analysis for the high adherence group, lumbago tended to be reduced, but in the low adherence group and the control group, it tended to be worse $(p=0.068)$. This overall ineffectiveness could be attributed to poor adherence.

There have been some studies in obese people in which a device to raise adherence was used. A systematic review [23] showed that booster interventions using telephone, e-mail, or the Internet strengthened the long-term duration of the effects, and an RCT [24] showed that brief monthly personal contact provided a modest benefit in sustaining weight loss. Such methods are effective to reinforce adherence, but it was assumed that there was a danger of increasing the burden on caregivers by adding too much mental stress originally $[8,9$, 13]. Furthermore, another study has reported that adherence to an unsupervised exercise regimen in obese women was poor [25]. However, supervision of female caregivers is a practical difficulty. At first, it was thought that considerably raising the readiness of the participants before the training (e.g., by OJT or off-JT) and a full-support system in the nursing home were essential.

Of note, a lumbago prevention approach, based on ergonomics to reduce physical load to the lower back, has been in practice for a long time. For example, it was reported that effective measures were the use of a heightadjusted bed [26], adoption of a lifting machine for patient transfer and bathing [27, 28], and wearing a lumbago prevention belt [29]. It has also been pointed out that care by the caregiver should be performed with the right posture to reduce the burden on their own lower back [30, 31]. Environmental maintenance and the placement of enough 
staff are ideals for the prevention of low back pain in nursing home caregivers [32], but the universal application of such concepts cannot occur in nursing homes in Japan because the reward is limited by the nursing care insurance. When caregivers assume a concept of "protecting one's body by oneself", comprehensive staff education on features such as the right posture for care, preventive exercise, and wearing a belt is necessary.

A meta-analysis based on 229 studies on gender differences in caregiver psychological and physical health and caregiving stressors suggested that women had higher levels of burden and depression, and lower levels of subjective well-being and physical health [13]. An interesting prospective cohort study reported that the management of occupational low back pain might be improved by the management of psychological distress [33]. In the present study, the CES-D and the MHS used were based on SF-8 for the other outcome measurements; however, as with the results for low back pain, a meaningful effect was not observed. For intervention studies for caregivers in the future, we will demand that the methodology assumes that lumbago will appear as a peripheral symptom not only of low back pain from physical load, but also from excessive mental stress. Although the intervention program in the present study reduced the burden on the caregiver as much as possible, adherence was very low. In staff education or training to prevent or reduce low back pain, for success to be achieved, it is necessary that the contents of the intervention be based not only on evidence, but also on feasibility. A precedent study set the following eight key areas of focus on feasibility: acceptability, demand, implementation, practicality, adaptation, integration, expansion, and limited efficacy [17]. We assume that these are useful concrete measures of intervention for caregivers.

The present study had some potential limitations. First, the calculation of the sample size of a cluster-RCT is different from the method for a personal unit [18, 34, 35]. However, this study allocated randomly by a nursing home unit, but the calculation of the sample size was based on an RCT of the personal unit. This method caused an error in the detection power. Second, in conjunction with the first limitation, a type II error was suggested due to the small number of withdrawals in each group, and the small number (15-23) of participants in each arm of the intervention groups in the subgroup analysis. In addition, an ITT analysis could not be performed. Third, the low back pain in this study was based on complaints of the participants; a diagnosis by orthopedists to specify a cause was not performed. Fourth, the timing of the evaluations, such as before or after work, was not constant because of shift work, and this may have caused information bias.

In conclusion, we utilized guidance by an orthopedist and an exercise instructor as on-the-job training, and we recommended stretching exercises for low back pain prevention for only $6 \mathrm{~min}$ every day to caregivers, but adherence was low, and there were few effects of the intervention. The importance of raising the caregivers' own readiness was shown, and identifying measures to prevent employees from resigning became clear as another basic problem to be solved.

Acknowledgments We would like to express our appreciation to Mr. S. Watanabe, Mr. T. Ohshiro, Mr. T. Honda, Ms. S. Moriyama, Mr. N. Kamada, Ms. M. Makishi, Ms. Y. Yamada, and Ms. R. Higashino for their cooperation in this study. The present study was registered as ID 000001836 by the University Hospital Medical Information Network Clinical Trials Registry (UMIN-CTR: http://www.umin.ac.jp/) in Japan. This study was supported by a research grant of the Akaeda Medical Research Foundation in 2009. In addition, this study received cooperation from the Hakujuji Corporation for recruitment of the participating groups.

Conflict of interest None.

\section{References}

1. Health and Welfare Statistics Association of Japan. Annual Statistical Report of National Health Conditions. Tokyo: Health and Welfare Statistics Association of Japan; 2006. p. 8-24 (in Japanese).

2. Hoshino J, Hori Y, Kondo T, Maekawa A, Tamakoshi K, Sakakibara H. Physical and mental health characteristics of female caregivers. Jpn J Public Health. 2009;56:75-86 (in Japanese with English abstract).

3. Lee S, Colditz GA, Berkman LF, Kawachi I. Caregiving and risk of coronary heart disease in US women. Am J Prev Med. 2003; 24:113-9.

4. Fujimura T, Yasuda N, Ohara H. Work-related factors of low back pain among nursing aides in nursing homes for the elderly. J Occup Health. 1995;37:89-98.

5. Dehlin O, Hedenrud B, Horal J. Back symptoms in nursing aides in a geriatric hospital. Scand J Rehab Med. 1976;8:47-53.

6. Fusano K, Kubo C, Ozaki K, Goto K, Tajima N. Risk factor on low back pain in the nurses and care workers. J Lumbar Spine Disord. 2007;13:113-20 (in Japanese with English abstract).

7. Josephson M, Vingard E. Workplace factors and care seeking for low-back pain among female nursing personnel MUSIC-Norrtalje Study Group. Scand J Work Environ Health. 1998;24:465-72.

8. Failde I, Gonzalez JL, Novalbos JP, Casais F, Marin J, Elorza J. Physical and occupational predictive factors for back pain among employees of a university hospital in southern Spain. Occup Med. 2000;50:591-6.

9. Ahlberg-Hulten GK, Theorell T, Sigala F. Social support, job strain and musculoskeletal pain among female health care personnel. Scand J Work Environ Health. 1995;21:435-9.

10. Kinugasa $T$, Nagasaki $H$, Ito $H$, Hashizume $K$, Furuna $T$, Maruyama $\mathrm{H}$, et al. Effect of physical fitness, sports activities, and aging on low back pain for women working in nursing home. Jpn J Phys Educ. 1995;40:151-60 (in Japanese with English abstract).

11. Nicholson PJ, D'Auria DAP. Shift work, health, the working time regulations and health assessments. Occup Med. 1999;49:127-37.

12. Tsukasaki K, Kido T, Makimoto K, Naganuma R, Ohno M, Sunaga K. The impact of sleep interruptions on vital measurements and chronic fatigue of female caregivers providing home care in Japan. Nurs Health Sci. 2006;8:2-9. 
13. Pinquart M, Sorensen S. Gender differences in caregiver stressors, social resources, and health: an updated meta-analysis. J Gerontol Psych Sci. 2006;61B:P33-45.

14. Frost H, Lamb SE, Moffett JAK, Moser JS. A fitness programme for patients with chronic low back pain: 2-year follow-up of a randomized controlled trial. Pain. 1998;75:273-9.

15. Kuukkanen T, Malkia E. Effects of a three-month active rehabilitation program on psychomotor performance of lower limbs in subjects with low back pain: a controlled study with a nine-month follow-up. Perceptual Mot Skills. 1998;87:739-53.

16. Cherkin DC, Deyo RA, Street JH, Hunt M, Barlow W. Pitfalls of patient education: limited success of a program for back pain in primary care. Spine. 1996;21:345-55.

17. Bowen DJ, Kreuter M, Spring B, Cofta-Woerpel L, Linnan L, Weiner D, et al. How we design feasibility studies. Am J Prev Med. 2009;36:452-7.

18. Campbell MK, Elbourne DR, Altman DG, CONSORT group. CONSORT statement: extension to cluster randomised trials. BMJ. 2004;328:48-64.

19. Boutron I, Moher D, Tugwell P, Giraudeau B, Poiraudeau S, Nizard R, et al. A checklist to evaluate a report of a nonpharmacological trial (CLEAR NPT) was developed using consensus. J Clin Epidemiol. 2005;58:1233-40.

20. Radloff LS. The CES-D scale: a self report depression scale for research in the general population. Appl Psychol Measure. 1977;1:385-401.

21. Fukuhara S, Suzukamo Y. Manual of the SF-8 Japanese version: Institute for Health Outcomes and Process Evaluation Research, Kyoto; 2004 (in Japanese).

22. Dias A, Dewey ME, D'Souza JD, Dhume R, Motghare DD, Shaji KS, et al. The effectiveness of a home care program for supporting caregivers of persons with dementia in developing countries: a randomized controlled trial from Goa. PloS One. 2008;4:e2333.

23. Silventoinen K, Sans S, Tolonen H. Trends in obesity and energy supply in the WHO MONICA project. Int J Obes Relat Metab Disord. 2004;28:710-8.

24. Svetkey LP, Stevens VJ, Brantley PJ, Appel LJ, Hollis JF, Loria $\mathrm{CM}$, et al. Comparison of strategies for sustaining weight loss: the weight loss maintenance randomized controlled trial. JAMA. 2008;299:1139-48.

25. Collay RC, Hills AP, O'Moore-Sullivan TM, Hickman IJ, Prince JB, Byrne NM. Variability in adherence to an unsupervised exercise prescription in obese women. Int J Obes. 2008;32: 837-44.

26. de Looze MP, Zinzen E, Caboor D, Heyblom P, van Bree E, van Roy $P$, et al. Effect of individually chosen bed-height adjustments on the low back stress of nurses. Scand J Work Environ Health. 1994;20:427-34.

27. Marras WS, Davis KG, Kirking BC, Bertsche PK. A comprehensive analysis of low-back disorder risk and spinal loading during the transferring and repositioning of patients using different techniques. Ergonomics. 1999;42:904-26.

28. Owen BD. Preventing injuries using an ergonomic approach. AORN J. 2000;72:1031-6.

29. Lavender SA, Thomas JS, Chang D, Andersson GBJ. Effect of lifting belt, foot movement, and lift asymmetry on trunk motions. Hum Factors. 1995;37:844-53.

30. Lieber SL, Rudy TE, Boston JR. Effects of body mechanics training on performance of lifting. Am J Occup Therapy. 2000; 54:166-75.

31. Skotte JH. Estimation of low back loading on nurses during patient handling tasks: the importance of bedside reaction force measurement. J Biomech. 2001;34:273-6.

32. Lagerstron M, Hansson T, Hagberg M. Work-related low-back problems in nursing. Scand J Work Environ Health. 1998;24: 449-64.

33. Feyer AM, Herbison P, Williamson AM, de Silva I, Mandryk J, Hendrie L, et al. The role of physical and psychological factors in occupational low back pain: a prospective cohort study. Occup Environ Med. 2000;57:116-20.

34. Whellan DJ, Ellis SJ, Kraus WE, Hawthorne K, Pina IL, Keteyian SJ, et al. Method for establishing authorship in a multicenter clinical trial. Ann Intern Med. 2009;151:414-20.

35. Hayers RJ, Bennett S. Simple sample size calculation for clusterrandomized trials. Int J Epidemiol. 1999;28:319-26. 